\title{
Early Antecedents of Childhood Impulsivity: The Role of Parent-Child Interaction, Cognitive Competence, and Temperament
}

\author{
Sheryl L. Olson, ${ }^{1,3}$ John E. Bates, ${ }^{2}$ and Kathryn Bayles ${ }^{2}$
}

This prospective longitudinal investigation examined early mother-child interaction as a predictor of children's later self-control capabilities. Multimethod assessments of mother-child relationships, primarily focused on observed relationship qualities in the home, were conducted during the first 2 years and related to children's later impulse control capabilities. Child cognitive competence and temperament assessed during the 2nd year were also related to later impulsivity. Follow-up assessments of children's impulsivity were conducted at age $6(\mathrm{~N}=79)$, using a variety of laboratory measures. Findings indicated that responsive, cognitively stimulating parenttoddler interactions in the 2nd year modestly predicted later measures of cognitive nonimpulsivity and ability to delay gratification. Security of motherinfant attachment predicted the same outcomes, but only for boys and not for girls. Child cognitive competence in the 2 nd year also consistently predicted children's later impulse control capabilities, although this was not true for measures of child temperament. Overall, the findings support a multidimensional and developmental conceptualization of the early antecedents of childhood impulsivity.

The emergence of self-regulation is one of the most significant developmental landmarks of the early childhood period (Bandura, 1977; Luria, 1961;

This research was supported by NIMH grants MH28018 to J. E. Bates and MH38605 to S. L. Olson. Portions of this research were presented at the biennial meeting of the Society for Research in Child Development, Baltimore, April 1987. The authors thank the families who participated, and others whose help was essential in data collection: Beth Ridge, Melinda Monroe, Jeff Harness, and Christine Maslin.

${ }^{1}$ Department of Psychology, University of Michigan, Ann Arbor, Michigan 48109-1346.

${ }^{2}$ Department of Psychology, Indiana University, Bloomington, Indiana 47405.

${ }^{3}$ Address all correspondence to S. L. Olson, Department of Psychology, University of Michigan, 580 Union Drive, Ann Arbor, Michigan 48109-1346. 
Mahler, Pine, \& Bergman, 1975). The construct of childhood self-control has immense clinical relevance as well. Self-control deficits are directly relevant to two major childhood behavior disorders, attention deficit and undersocialized aggressive conduct disorder. In addition, self-control deficits are associated features of many other problems of childhood adaptation, including specific learning disabilities (Lahey, Vosk, \& Habif, 1981), mental retardation (Kopp, Krakow, \& Vaughn, 1983), and peer rejection (Pelham $\&$ Bender, 1982). However, despite the importance of the construct, we know very little about the developmental origins of self-regulatory competence.

\section{DEVELOPMENTAL ANTECEDENTS OF SELF-REGULATION}

Kopp (1982) has placed the emergence of self-control in a developmental framework. Self-regulatory competence emerges gradually from a series of discontinuous developmental phases. With the appearance of representational thought and recall memory during the latter half of the 2nd year, children begin to internalize social standards. For example, many children of this age will inhibit prohibited actions owing to remembered information. However, children's flexible monitoring, or "self-regulation," does not develop until the 3rd or 4th year of life. Kopp's framework, focusing on normative developmental progressions, provides a good basis for raising the question of how individual differences in self-control arise. Potential early developmental influences on children's later self-control are outlined below.

\section{Parent-Child Relationship Influences}

Most developmental theorists concur that early forms of self-control are necessarily linked to caregivers' behavior: "Control" is imposed externally first, then gradually internalized. However, there is little consensus concerning the types of parental behaviors thought to be most facilitative of children's self-control. Several different themes are apparent. First, maternal sensitivity and responsiveness has been associated with children's willingness to comply with adult authority (Baumrind, 1979; Lytton, 1977; Parpal \& Maccoby, 1985). A related construct, quality of mother-infant attachment, has also been linked to child compliance with the mother in several studies (e.g., Londerville \& Main, 1981; Matas, Arend, \& Sroufe, 1978). Finally, Sroufe and his colleagues (Sroufe, 1983; Erickson, Sroufe, \& Egeland, 1985) have shown that infants rated as insecurely attached to their caregivers show social-adaptational problems in preschool and kindergarten, including ag- 
gressive and inattentive behavior. The latter findings have not been adequately replicated (Bates \& Bayles, 1988).

Parental disciplinary styles have also been viewed as critical antecedents of appropriate child compliance (Patterson, 1982; Schaffer, 1984). Clear, consistent, but nonpunitive parental control has been correlated with good child compliance in many previous reports, spanning age ranges from toddlerhood to school age (e.g., Kuczynski, 1984; Lee \& Bates, 1985; Lytton, 1977; Minton, Kagan, \& Levine, 1971; Schaffer \& Crook, 1979, 1980). For example, Schaffer and Crook $(1979,1980)$ observed control techniques used by mothers of toddlers in a laboratory play situation. The most consistent positive predictors of child compliance were consistency of rule enforcement, encouragement of mature behavior, and use of praise as a reward. Frequency of physical punishment was the most important predictor of noncompliance.

In summary, there is a substantial empirical literature linking qualities of maternal behavior, such as responsiveness, sensitivity, and consistent control, to individual differences in child compliance to authority. Our work was intended to build on these previous studies in several ways. First, although compliance is an important manifestation of self-regulation, the construct of self-control encompasses a broader range of capabilities that should be examined in relation to socialization influences. Furthermore, with the possible exception of some infant attachment studies, the literature on parental socialization of childhood self-control is concurrent in scope. "Deviant" parental behavior styles could be antecedent to child noncompliance/impulsivity, or could reflect attempts to cope with an already "difficult" child. Finally, there are characteristics of children that could explain observed relationships between parental behavior and child self-regulation. Two individual difference variables hypothesized to be important in the development of impulse control, cognitive competence and temperament, are briefly discussed below.

\section{Cognitive Competence Influences}

Self-regulatory behaviors reflect complex cognitive processes such as problem solving, memory, and "internalized" speech (Luria 1961; Mischel \& Patterson, 1979; Vygotsky, 1962; Wertsch, 1984). However, the relationship between individual differences in children's cognitive competence and the development of self-regulatory skills is not well understood. To what extent does verbal/cognitive competence mediate children's developing impulse control capabilities? Furthermore, positive correlations between responsive, nonrestrictive parenting and children's self-control may primarily reflect chil- 
dren's cognitive competence, since these relationship qualities have been related to early cognitive maturity in many previous studies.

\section{Temperament Influences}

Finally, biologically related child response propensities such as temperamental irritability, unsoothability, or stimulation seeking are widely believed to predispose children to develop impulsivity problems (Buss \& Plomin, 1984; Thomas, Chess, \& Birch, 1968). There is some empirical support for this idea. Carey, Fox, and McDevitt (1977) reported predictive links between parent perceptions of infant difficultness at 6 months and impulsive cognitive style (on the Matching Familiar Figures Test) during the school-age years. More recently, Bates and his colleagues have shown that early child irritability and resistance to control, as reported by the mother, predict maternal ratings of aggression and hyperactivity in the preschool years (Bates \& Bayles, 1988; Bates, Maslin, \& Frankel, 1985). However, empirical data are scanty on the role of temperament in behavior problems, and temperamental influences have not been explored at all for many other aspects of self-regulatory competence.

\section{PURPOSE}

The major purpose of this study was to identify the relative contributions of different parent-child interaction antecedents to children's later selfregulatory abilities. A broad-band, multimethod approach to the assessment of children's self-regulatory skills was adopted, because previous studies have not supported a notion of impulsivity as a unitary trait construct (see Milich \& Kramer review, 1984). Research questions were as follows: (1) Do qualities of early parent-child interaction predict individual differences in children's impulsivity over a long time span? In light of previous research, we expected that measures of maternal sensitivity and responsiveness would be positively predictive of children's later self-regulatory skills, particularly measures of child compliance, and that measures of restrictive, punitive maternal behavior would be negatively predictive. (2) At what point during the first 2 years does social interaction become predictive of later childhood impulsivity? (3) Finally, to what extent are any observed relationships between early social interaction and later impulsivity a function of variations in children's cognitive competence or temperament? If early social interaction patterns are important antecedents of childhood impulsivity, they should make significant contributions to outcome measures even when other relevant variables are controlled for. 


\section{METHOD}

\section{Subjects}

The initial basis of this study was a 2-year longitudinal investigation assessing concurrent and predictive interrelations between parent-perceived difficult infant temperament and mother-infant interaction. Using published birth notices, 168 subjects were initially recruited when the infants neared 6 months of age. Family occupation status was predominantly middle-middle class, but ranging from upper-middle- to working-class levels. The sample was fairly evenly divided on infant gender and parity. Further details about the sample are in Bates, Olson, Pettit, and Bayles (1982).

Eighty mother-child pairs $(44 \mathrm{M}, 36 \mathrm{~F})$ participated in follow-up procedures when the children were 6 years old. Most of the sample attrition was due to families' having moved out of town. A few of the families were lost because of unwillingness or inability to participate, but most such dropouts occurred in the 1st year of the study. Analyses suggested no systematic differences in demographic or other study characteristics in the families who dropped out as compared with those who continued (Bates et al., 1985). Families were paid for participating in the follow-up study. Sample distribution characteristics were similar to those of the basic study (19\% working, $63 \%$ middle, $17 \%$ upper-middle class; $47 \%$ firstborn).

\section{Overview of Procedures}

This was a large multivariate study of caregiver-infant relationships and their long-term developmental sequelae. Within each of the early assessment periods $(6,13$, and 24 months), measures of two central caregiver-child relationship constructs were extracted for use as predictors in the current study: maternal restrictiveness, and maternal stimulation/responsiveness. Measures of infant temperament and cognitive competence collected at age 2 were also included in this study. Specific measures are described below.

\section{Procedure at 6 Months}

Mother-infant interaction was assessed during two 3-hour home visits (approximately 1 week apart) using naturalistic observation procedures and Caldwell's Home Observation for Measurement of the Environment scales (HOME; Caldwell \& Bradley, 1985). Data were collected by trained women observers. Events were tallied on a continuous basis, using Datamyte electronic event recorders and a code book of 9 infant and 18 mother be- 
haviors. Factor analyses of the observation data were conducted separately for mother and infant behaviors (Bates et al., 1982.) The factor scale Mother Affectionate Contact was used in the current study, because it primarily indexed warm maternal responsiveness to the infant. The interobserver reliability coefficient for this scale (based on Pearson correlation) was .91.

At the end of the second home visit, observers completed Caldwell's HOME scale. The HOME subscale Avoidande of Restriction was used in this study as an index of maternal restrictiveness. The subscale Emotional and Verbal Responsivity was added to the Affectionate Contact scale after both scales were standardized, to constitute a composite measure of maternal responsiveness. This composite predictor was labeled Warm Responsiveness.

\section{Procedure at 13 Months}

At 13 months of age, 139 of the mother-infant pairs participated in follow-up procedures. Home observation data were collected by trained observers in one 3-hour session using the methods described above. In order to reduce halo effects in most cases an observer did not visit the same family at two successive ages. Codes for mother (16) and infant (15) were factoranalyzed separately (see Pettit \& Bates, 1984, for a detailed description of data reduction procedures at age 13 months). At the end of the observation, the Home Inventory was again completed, omitting several items requiring interview.

Predictor variables used in this study were based on standardized combinations of the molecular behavior scales with conceptually and empirically related HOME ratings. The first predictor variable, Teaching and Responsiveness, was defined by the molecular behavior composite Mother Teaching (scale reliability coefficient $=.86$; mother names objects, questions, offers and demonstrates toys, etc., for the infant) and by the HOME subscale Emotional and Verbal Responsivity. The second predictor variable, Nonrestriction, was defined by the molecular behavior composite Mother Management (scale reliability coefficient $=.92$; mother scolds or warns infant, directs infant's behavior, and takes objects away from infant) and by the HOME subscale Avoidance of Restriction.

Finally, for the second half of the sample $(n=74)$, there was a separate visit to an unfamiliar room for the strange situation assessment of attachment (Ainsworth, Blehar, Waters, \& Wall, 1978). For 68 dyads, attachment security could be confidently judged ( $66 \%$ secure, $13 \%$ anxious/avoidant, $16 \%$ anxious resistant, $5 \%$ mixed anxious patterns). Standard attachment classifications were converted to a 3-point scale of attachment security (see Bates et al., 1985) so we could analyze attachment security as a continuous 
variable. Avoidant and resistant infants were assigned a score of 1; B1, B2, and B4 infants were assigned a score of 2; and B3 infants (the Ainsworth et al. (1978) "optimally attached" group) were assigned a score of 3.

\section{Procedure at 24 Months}

At 24 months of age 120 of the mother-infant pairs participated in follow-up procedures. Mothers completed the 24-month version of the Child Characteristics Questionnaire. This questionnaire consists of 32 7-point scales relating to different aspects of difficult child temperament. High scores on the main questionnaire scale describe children who are perceived as high in negative emotionality, often expressed in the context of parent-child conflict (Lee \& Bates, 1985). Two 3-hour home observations were conducted within approximately 1 week. Twenty-three child and 28 mother behavior frequency codes were averaged across days and factor-analyzed separately. Factor scales were computed as for the 6-and 13-month assessments. At the end of the second home visit, observers recorded their global impressions of each dyad on the 30-item Post Observation Questionnaire (POQ; Olson, Bates, \& Bayles, 1982, 1984). Finally, during a separate lab session the children were administered the Bayley Mental Scale (Bayley, 1969) by a different woman examiner.

Two 24-month scales were used as mother-child relationship predictors in this study. The first, Mother Verbal Stimulation, was a molecular factor composite defined by frequencies of positive verbal initiations and responses vis-á-vis the child (reliability coefficient $=.82$ ). The second predictor scale, Nonpunitive Discipline, was defined by the POQ scales Clear, Consistent Control and Mother Nonpunitive minus the molecular behavior composite Mother Negative Control (reliability coefficient $=.75$; mother scolds, warns, physically punishes, or restrains child).

\section{Procedure at 6 Years}

Follow-up assessments, primarily focused on various aspects of impulsivity, were carried out when the children were 6 years of age. The following methods were used.

Laboratory Tasks. Children participated in a series of laboratory tasks, each designed to measure a major operational definition of self-control. Procedures 1-4 were administered during the first laboratory visit, in that order. Behavioral observations were conducted during a second laboratory visit, scheduled 1 week later. Descriptions of each task are as follows:

1. The Matching Familiar Figures Test is a measure of cognitive impulsivity developed by Kagan, Rosman, Albert, and Phillips (1964) and used 
extensively by researchers to assess childhood self-control. A single drawing of a familiar object, the standard stimulus, is paired with an array of six variants of the drawing. All but one of the variants differ slightly from the standard stimulus, and the child must choose the alternative that matches the standard stimulus exactly. Dependent variables are average latency to first response and average number of errors.

2. Draw-a-line-slowly and Walk-a-line-slowly are measures of the ability to inhibit fine and gross motor movements in response to situational demands (Maccoby, Dowley, Hagen, \& Degerman, 1965). The following version of the test was adapted by Arend, Gove, and Sroufe (1979). Draw-a-line-slowly: Each child is given an $81 / 2 \times 11$ " piece of paper with two "telephone poles" drawn in black ink. The child is given practice using a ruler, then asked to connect the poles by drawing a straight line. After two trials at regular speed, the child is asked to draw the line as slowly as possible ( 2 trials). Walk-aline-slowly: The child is asked to walk a 6-foot-long "sidewalk" (marked with tape on the floor) at regular speed ( 2 trials/and then as slowly as possible ( 2 trials). Both tasks yield regular speed and inhibition (average regular minus average slow trials) scores.

3. Delay of gratification is a measure of self-control described in Arend et al. (1979). In this task, the experimenter "discovers" a small wrapped gift and informs the child that he or she may have it "later". A 2- to 3-minute cover task is then carried out, during which the experimenter records any attempts to open the gift prematurely. In this study, the cover task involved asking the child to color in a series of geometric shapes according to a designed color-coding scheme. The dependent measure is the amount of time (in seconds) that elapses before the child takes the gift.

4. In the examiner ratings, subsequent to testing, examiners rated each child's level of task orientation versus distractibility on a 5-point scale. High scores indicated good task orientation during testing. Interrater reliability for this scale averaged $.81(n=42$ paired observations during which an examiner and a child were observed by a corater behind a one-way mirror).

Means and standard deviations for the different tests of impulsivity are shown in Table I. To evaluate the complex pattern of correlations among

Table I. Means and Standard Deviations for Tests of Impulsivity $^{a}$

\begin{tabular}{lrr}
\hline Measure & Mean & \multicolumn{1}{c}{$S D$} \\
\hline MFFT-RT & 17.54 & 11.38 \\
MFFT-errors & 1.20 & 0.59 \\
Motor inhibition-draw & 29.85 & 22.76 \\
Motor inhibition-walk & 17.49 & 15.49 \\
Delay of gratification-response time & 83.13 & 22.66 \\
\hline${ }^{a} N=79$. & &
\end{tabular}


Table II. Factor Analysis of Impulsivity Test Variables $^{a}$

\begin{tabular}{lrr}
\hline & \multicolumn{2}{c}{ Factors } \\
\cline { 2 - 3 } Variables & \multicolumn{1}{c}{1} & \multicolumn{1}{c}{2} \\
\hline MFFT-reaction time & .80 & .22 \\
MFFT-errors & .62 & -.30 \\
Motor inhibition-draw & .65 & .20 \\
Motor inhibition-walk & .78 & -.10 \\
Task orientation & .12 & .76 \\
Delay of gratification & .08 & .74 \\
\hline
\end{tabular}

${ }^{a} N=79$. Principal components analysis, varimax rotation. Initial eigenvalues: $2.63,1.14,0.95,0.78$, $0.62,0.54$.

the measures of impulsivity, and perhaps to summarize the measures in a more manageable subset of composite variables, principal components analyses were carried out. The following variables were entered into the analysis: Matching Familiar Figures Test reaction time and error scores; response time on the delay of gratification task; motor inhibition scores (average regular minus average slow trials, walking and drawing), and rated task orientation. As shown in Table II, the principal components analysis resulted in two orthogonal dimensions of impulsivity, which accounted for $44.5 \%$ of the total variance. One factor, labeled Inhibitory Control, was defined by the MFFT reaction time score and motor inhibition scores for the drawing and walking tasks, with a negative loading for the MFFT error score. Thus, this dimension represented degree of cognitive control over behavior in highly structured task situations. The second factor dimension, labeled Patient and Task-Oriented, was defined by response time on the delay of gratification task and the examiner's rating of good task orientation. Composite scales (unweighted) were constructed from the standardized individual variables that defined each factor.

Observation. In order to obtain behavioral observations relevant to impulse control, a modified version of the observation procedure reported in Milich, Loney, and Landau (1982) was used. Observers behind a one-way glass recorded data during three 10 -minute observation periods. The room was equipped with a small work table and a variety of age- and sexappropriate toys. During the free-play period, each child was ushered into the room and allowed to play as he or she wished for 10 minutes. During the restricted task period, the child was asked to sit down at the small table. A set of geometric shapes drawn in black ink on $8 \frac{1}{2} \times 11$ " pieces of white paper was presented. Small representations of the shapes were depicted at the bottom of the page, each with a different color. The child's task was to color in each large shape with crayon, matching its hue to the key below. Additional pages of shapes to be colored were made available. The child was 
told to stay in the chair and color until the experimenter returned, and that it was strictly forbidden to touch or play with the toys in the room. Dependent variables were percentage of times off-task, percentage of times out of seat, and number of times forbidden toys were touched or played with. During the incentive restricted task period, the above procedure was repeated, except that this time the child was told he or she would receive a prize for each worksheet completed. Milich et al. did not use the incentive restricted task; we added it as a means of examining motivational variance in children's selfcontrol behaviors. Reliability checks, conducted using two independent observers, indicated high levels of agreement on all variables (range $=$ $90-100 \%)$.

Observation data were composited into two higher-order scales, labeled Noncompliance and Off Task. Noncompliance indexed violations of the adult directive to remain seated and refrain from playing with toys in the room. This scale was defined by relative frequencies of out-of-seat behavior and toy touching in the restricted task conditions (Cronbach's alpha $=.57$ ). The second scale, Off Task, indexed relative frequencies of off-task behavior (e.g., clear deflections of attention from the coloring task) in the restricted task conditions. The correlation between off-task behavior in the nonincentive and incentive restricted task conditions was $.51(p<.001)$.

\section{RESULTS}

Measures of impulsivity at age 6 were intercorrelated with measures of mother-child interaction assessed during the first 2 years, and with measures of child cognitive competence and temperament assessed at age 2 . An overview of measures used in data analyses is contained in Table III. Significant zero-order correlations are summarized below, according to each major category of predictor variables. $N$ s for the bivariate analyses ranged from 67 to 77, with some exceptions. ${ }^{4}$ Where appropriate, multiple regression analyses were subsequently conducted to test alternative hypotheses about the meaning of the zero-order patterns.

\section{Mother-Child Relationship Antecedents}

Parent-child relationship antecedents of children's later self-regulatory competence are shown in Table IV, computed separately by child sex.

\footnotetext{
${ }^{4}$ The number of separate correlations suggests the need for caution in interpretation. Since our aim was to see any consistent, theoretically interesting pattern of results, we did not adjust significance levels upward. However, we did use two-tailed tests in all instances, even where predictions could be made in advance of the direction of correlation. Most $N$ 's for the bivariate analyses ranged from 67 to 77 . However, there were exceptions when teacher ratings were used as outcome criteria $(N=45)$ and when attachment security was used as a predictor variable $(N=32)$, since Strange Situation data were available only for the second birth cohort.
} 
Table III. Overview of Measures

\begin{tabular}{ll}
\hline $\begin{array}{l}\text { Age } 6 \text { months } \\
\text { Mother-infant interaction }\end{array}$ & $\begin{array}{l}\text { 1. Warm responsiveness } \\
\text { 2. Avoidance of restriction }\end{array}$ \\
$\begin{array}{ll}\text { Age } 13 \text { months } \\
\text { Mother-infant interaction }\end{array}$ & $\begin{array}{l}\text { 1. Teaching and responsiveness } \\
\text { 2. Nonrestriction }\end{array}$ \\
$\begin{array}{l}\text { 3. Security of attachment } \\
\text { Age } 24 \text { months }\end{array}$ & $\begin{array}{l}\text { 1. Verbal stimulation } \\
\text { Mother-child interaction }\end{array}$ \\
$\begin{array}{ll}\text { Child cognitive competence } \\
\text { Child temperament }\end{array}$ & $\begin{array}{l}\text { Bayley MDI } \\
\text { Age } 6 \text { years }\end{array}$ \\
Measures of impulsivity & 1. Inhibitory control (factor scale) \\
& 2. Patient and task-oriented (factor scale) \\
& 3. Noncompliance (behavioral observation)
\end{tabular}

Although mother-infant interaction in the 1st year was mostly unrelated to 6-year outcomes, qualities of parent-child interaction during the 2nd year of life were predictive of children's later impulse control capabilities, with sex differences in the patterning of these correlations. Boys and girls who experienced high rates of positive verbal interaction at age 2 tended to score highly on the Patient and Task-Oriented scale, an index of delay ability and task orientation during testing. Other patterns of predictive relationships were sex-specific. Boys whose mothers were relatively nonrestrictive and clear, consistent, and nonpunitive in discipline tended to score highly on the composite index of cognitive control over behavior. Similarly, boys whose mother-infant attachment relationships were rated highly secure tended to score highly on laboratory measures of cognitive control over impulses, delay of gratification, and task orientation. Security of mother-child attachment did not predict later impulsivity in girls, however. Finally, girls who experienced high maternal responsiveness and intellectual stimulation at ages 13 and 24 months tended to be more highly task-oriented and compliant than others during the observation tasks. Boys' behavior during observation was not predicted by their early social relationships.

\section{Child Cognitive Competence Antecedents}

Correlations between early cognitive competence and children's later self-regulatory competence were computed separately by child sex, and for both sexes combined. Only the full-sample correlations are shown here, because the pattern of results was very similar for boys and girls. As shown in Table V, child cognitive competence at 24 months consistently predicted 


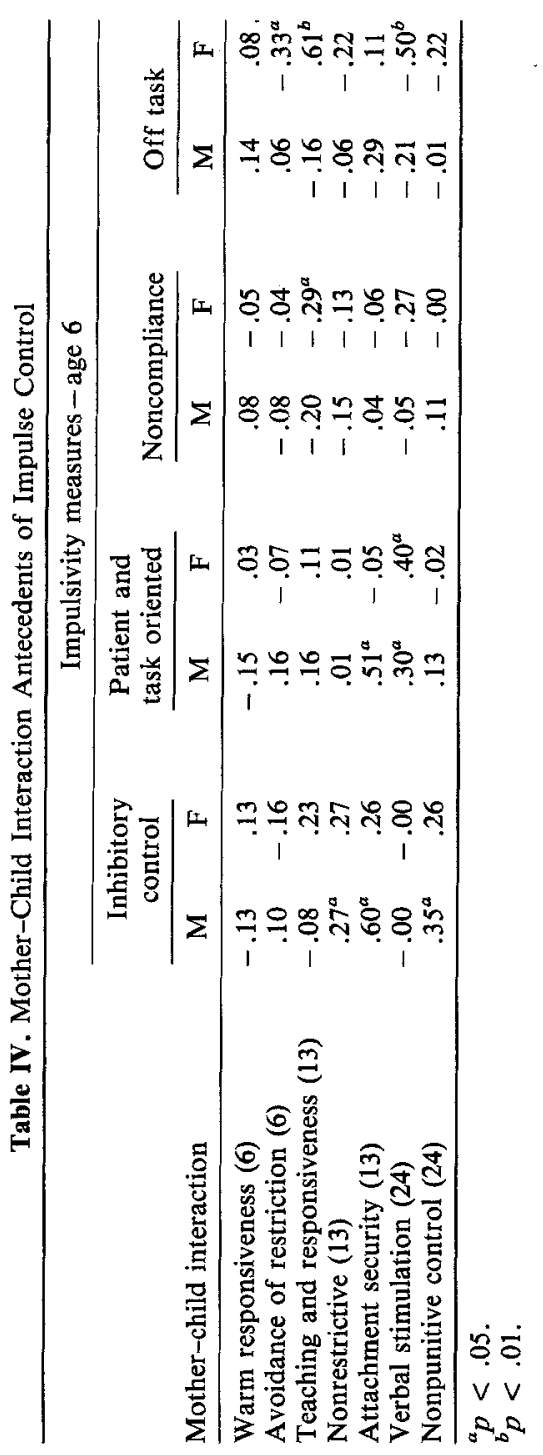


Table V. Child Cognitive Competence Antecedents of Impulse Control

\begin{tabular}{lc}
\hline Measures of impulsivity-age 6 & Bayley MDI-age 24 months \\
\hline Inhibitory control & $.28^{a}$ \\
Patient and task-oriented & $.23^{a}$ \\
Noncompliance & -.01 \\
Off task & $-.23^{a}$ \\
\hline${ }^{a} p<.05$ &
\end{tabular}

children's later impulse control outcomes. In every case, higher levels of cognitive development modestly predicted higher levels of impulse control.

\section{Child Temperament}

Difficult toddler temperament (age 24 months) was also intercorrelated with children's self-control outcomes. Contrary to expectation, no significant relationships were obtained. Recomputing these correlations separately by child sex did not alter this general pattern of nonrelationships.

\section{Multiple Regression Analyses}

The bivariate results indicated that measures of both parent-child interaction and child cognitive competence in the 2 nd year predicted laboratory indexes of impulsivity at age 6 . However, because these two sets of predictor variables have been found to be intercorrelated (Olson et al., 1984), additional multiple regression analyses were needed to determine whether early mother-child interaction made an independent contribution to the variance in age 6-year outcomes. Hierarchical multiple regression analyses were conducted using two aggregated impulsivity outcomes as dependent measures: the sum of the two test scales, and the sum of the two behavioral observation scales. In each analysis, variables were entered one at a time in the following order: 24-month cognitive competence, 13-month mother-child interaction measures that had significant zero-order correlations with the dependent measure, then 24-month mother-child interaction correlates of the dependent measure. As shown in Table VI, similar predictive patterns were found for both composite measures. Parent-child interaction measures made significant independent contributions to the variance in the outcome measures beyond that shared with child cognitive competence.

Finally, as noted in the previous section, difficult temperament did not predict children's later impulsivity. However, it seemed possible that temperament could interact with qualities of caregiving in relation to childhood impulse control. To examine this possibility, hierarchical multiple regression analyses were conducted with caregiver-child interaction correlates of im- 
Table VI. Multiple Regression Analysis: Predictors of Impulsivity

\begin{tabular}{llll}
\hline & $R$ & $R^{2}$ increase & $F$ \\
\hline Test composite & & & \\
$\quad$ Bayley MDI & .17 & .02 & 0.81 \\
Attachment security & .50 & .25 & $4.46^{a}$ \\
$\quad$ Verbal stimulation & .61 & .38 & $5.23^{b}$ \\
Behavioral composite & & & \\
$\quad$ Bayley MDI & .28 & .08 & $5.09^{a}$ \\
Teaching and responsiveness & .38 & .14 & $4.97^{a}$ \\
$\quad$ Verbal stimulation & .41 & .17 & $3.80^{a}$ \\
\hline${ }^{a} p<.05$. & & & \\
${ }^{b} p<.01$. & & & \\
\end{tabular}

pulse control measures entered first (separately by age period), followed by difficult temperament $\times$ caregiver-child interaction. The interaction terms did not make significant contributions to the variance in later impulsivity beyond that shared with qualities of caregiving alone.

\section{DISCUSSION}

Early social, cognitive, and temperamental antecedents of children's later impulse control were examined in the current study. First, we asked whether the measures of caregiver-child interaction assessed during the first 2 years of life would predict individual differences in impulse control at age 6. Given the concurrent relationships found in previous research, we expected that high maternal responsiveness, low restrictiveness, and clear, consistent discipline would predict children's later impulse control, particularly compliance with authority. These hypotheses were partly supported. Qualities of social interaction assessed at age 6 months generally did not predict 6-year outcomes. However, qualities of caregiver-child interaction assessed at 13 and 24 months were modestly predictive of later self-regulatory competence. Ability to remain task-focused and to delay gratification was predicted by maternal responsiveness to the child's verbal communications at age 2 , suggesting that responsive, cognitively enriching social transactions may be important antecedents of children's delay abilities.

Other predictive patterns were sex-specific. Boys who were rated securely attached to their caregivers in infancy tended to show good cognitive impulse-control and delay capabilities at age 6 . The finding that infant attachment security predicted later impulsivity for boys but not for girls is consistent with findings from one previous study. Lewis, Feirig, McGuffog, and Jaskir (1984) reported that insecurely attached males had higher externalizing behavior problem scores at age 6 than others. However, other investigators have not found sex differences in relationships between early 
attachment and later adjustment (Bates \& Bayles, 1988; Erickson et al., 1985), indicating a need for further research into this issue.

Similarly, boys whose mothers were relatively nonrestrictive and skilled in discipline during the 2nd year tended to score more highly than others on a measure of cognitive impulse control. Patterns of maternal control did not predict girls' later impulse control, although it is noteworthy that the correlations were marginally significant and in the expected direction. Finally, girls' ability to remain on task during the restricted observation was predicted by frequency of positive, responsive verbal interactions at 13 and 24 months, often centered around teaching themes. Of all the impulse control measures, the restricted task paradigm most closely paralleled academic classroom situations. Therefore, it is not surprising that early "educational" interactions predictive of good cognitive skills also predicted task-focused behavior. However, it is unclear why this relationship pertained only to girls and not to boys.

Further analyses revealed that cognitive competence at age 2 was consistently correlated with children's later self-regulatory skills, raising questions about the uniqueness of relationships between parent-child interaction and age 6 outcomes. However, hierarchical multiple regression analyses revealed that both child cognitive competence and caregiver-child interaction made significant contributions to the variance in later child impulsivity, supporting a multidimensional view of the antecedents of childhood impulse control.

Finally, we examined the role of child temperament as a precursor of children's later impulse control capabilities. Contrary to expectation, measures of difficult temperament failed to predict indexes of impulsivity at age 6 , either alone or in combination with caregiver-child interaction measures. In other studies, we have found that ratings of difficult infant temperament predict maternal ratings of both externalizing behavior problems (such as aggression and noncompliance) and internalizing (such as fears and depression) at ages 3, 4, 5, and 6 (Bates \& Bayles, 1988; Bates et al., 1985). We conclude that there is a significant long-term continuity in mothers' perceptions of child deviance, which may have important implications for children's self-control in the context of the mother-child relationship (e.g., compliance with maternal authority). However, the temperament measures contributed little to our understanding of the development of self-control capabilities assessed outside the mother-child relationship.

\section{CONCLUSION}

This study provides modest support for the hypothesis that responsive, sensitive, and cognitively enriching mother-child interactions are important 
precursors of childhood impulse control. Our findings extend this hypothesis to a long-term predictive framework, and to measures of child impulsivity assessed independently of the mother-child relationship. The hypothesis that patterns of excessive and/or ineffective maternal control would predict child impulsivity received more limited support. Punitive control and inconsistent discipline did predict later cognitive impulsivity in boys, a finding that is broadly consistent with research on older children (e.g., Patterson). The failure of this pattern to generalize to girls or to other measures of self-control may reflect our choice of outcome measures. It is conceivable that patterns of maternal control most strongly predict child compliance with the mother (e.g., Lee \& Bates, 1985) or more global aspects of undercontrolled social behavior (e.g., peer aggression, noncompliance in the classroom). We will examine this possibility in future studies.

Our findings also indicate the necessity of adopting a developmental framework when examining antecedents of later child functioning. Measures of the social environment assessed during the 1st year of life did not predict 6-year outcomes, whereas caregiver-child interaction in the 2 nd year did predict children's later self-control. If these later assessments of the caregiving environment had not been available, we would have concluded that quality of early caregiving is completely independent of children's later development. Furthermore, the significant relationships between caregiving in the 2nd year and children's later development may primarily reflect continuity in qualities of the caregiving environment, not "unique effects" of early social experience.

Finally, a theory of the origins of self-control focusing solely on qualities of the social environment would be incomplete. Child cognitive competence at age 2 significantly predicted measures of later cognitive impulsivity, delay ability, and task orientation. Since the cognitive-linguistic underpinnings of childhood self-regulation have primarily been studied within a normative developmental framework, investigating how individual differences in cognitive competence mediate the development of self-control would be an important topic for further research. These combined findings best support Kopp's (1982) contention that aspects of caregiving environment and children's cognitive skills are important to the development of self-control, and extend this idea to a long-term individual difference framework.

\section{REFERENCES}

Ainsworth, M. D. S., Blehar, M. C., Waters, E., \& Wall, S. (1978). Patterns of attachment: $A$ psychological study of the strange situation. Hillsdale, NJ: Erlbaum.

Arend, R., Gove, F. L., \& Sroufe, L. A. (1979). Continuity of individual adaptation from infancy to kindergarten: A predictive study of ego-resiliency and curiosity in preschoolers. Child Development, 50, 950-959. 
Bandura, A. (1977). Social learning theory. Englewood Cliffs, NJ: Prentice-Hall.

Bates, J. E., \& Bayles, K. (1988). The role of attachment in the development of behavior problems. In J. Belsky \& T. Nezworsky (Eds.), Clinical Implications of attachment (pp. 253-295). Hillsdale, NJ: Erlbaum.

Bates, J. E., Maslin, C. A., \& Frankel, K. A. (1985). Attachment security, mother-child interaction and temperament as predictors of behavior problem ratings at three years. In I. Bretherton \& E. Waters (Eds.), Monographs of the Society for Research in Child Development, Special Issue: Growing points of attachment theory and research, 50 (1-2, Serial No. 209, pp. 167-193).

Bates, J. E., Olson, S. L., Pettit, G. S., \& Bayles, K. (1982). Dimension of individuality in the mother-infant relationship at 6 months of age. Child Development, 53, 445-461.

Baumrind, D. (1979). Current patterns of parental authority. Developmental Psychology Monograph, $41,(1, \mathrm{p}+2)$.

Bayley, N. (1969). Bayley Scales of Infant Development. New York: Psychological Corporation.

Buss, A. H., \& Plomin, R. (1984). Temperament: Early developing personality traits. Hillsdale, NJ: Erlbaum.

Caldwell, B., \& Bradley, R. (1985). Home observation for the measurement of the environment. Homewood, IL: Dorsey Press.

Carey, W. B., Fox, M., \& McDevitt, S. C. (1977). Temperament as a factor in early school adjustment. Pediatrics, 60, 621-624.

Erickson, M. F., Sroufe, L. A., \& Egeland, B. (1985). The relationship between quality of attachment and behavior problems in preschool in a high-risk sample. In I. Bretherton \& E. Waters (Eds.), Monographs of the Society for Research in Child Development, Special issue: Growing points of attachment theory and research, 50, (1-2, Serial No. 209, pp. 147-166).

Kagan, J., Rosman, B. L., Albert, J., \& Phillips, W. (1964). Information-processing in the child: Significance of analytic and reflective attitudes. Psychological Monographs, 78(1).

Kopp, C. B. (1982). The antecedents of self-regulation: A developmental perspective. Developmental Psychology, 18, 199-214.

Kopp, C., Krakow, J., \& Vaughn, B. (1983). Patterns of self-control in young handicapped children. In M. Perlmutter (Ed.), Minnesota symposium in child psychology (Vol. 16, pp. 93-128). Hillsdale, NJ: Erlbaum.

Kuczynski, L. (1984). Socialization goals and mother-child interaction: Strategies for long-term and short-term compliance. Developmental Psychology, 20, 1061-1073.

Lahey, B. B., Vosk, B. N., \& Habit, V. L. (1981). Behavioral assessment of learning-disabled children: A rationale and strategy. Behavioral Assessment, 3, 3-14.

Lee, C., \& Bates, J. E. (1985). Mother-child interaction at age two years and perceived difficult temperament. Child Development, 56, 1314-1325.

Lewis, M., Feiring, C., McGuffog, C., \& Jaskir, J. (1984). Predicting psychopathology in sixyear-olds from early social relations. Child Development, 55, 123-136.

Londerville, S., \& Main, M. (1981). Security of attachment, compliance, and maternal training methods in the second year of life. Developmental Psychology, 17, 289-299.

Luria, A. R. (1961). The role of speech in the regulation of normal and abnormal behavior. London: Pergamon Press.

Lytton, H. (1977). Correlates of compliance and the rudiments of conscience in two-year-old boys. Canadian Journal of Behavioral Science, 9, 243-251.

Maccoby, E., Dowley, E., Hagen, J., \& Degerman, R. (1965). Activity level and intellectual functioning in normal preschool children. Child Development, 36, 761-770.

Mahler, M., Pine, F., \& Bergman, A. (1975). The psychological birth of the human infant. N.Y.: Basic.

Matas, L., Arend, R. A., \& Sroufe, L. A. (1978). Continuity of adaptation in the second year: The relationship between quality of attachment and later competence. Child Development, 49, 547-556.

Milich, R., \& Kramer, J. (1984). Reflections on impulsivity: An empirical investigation of impulsivity as a construct. In K. Gadow (Ed.), Advances in learning and behavioral disabilities (Vol. 3, pp. 57-94). Greenwich, CT: JAI Press. 
Minton, C., Kagan, J., \& Levine, J. A. (1971). Maternal control and obedience in the twoyear-old. Child Development, 42, 1873-1894.

Mischel, W., \& Patterson, C. J. (1979). Effective plans for self-control in children. In A. Collins (Ed.), Minnesota symposium on child psychology. Hillsdale, NJ: Erlbaum.

Olson, S. L., Bates, J. E., \& Bayles, K. (1982). Maternal perceptions of infant behavior: A longitudinal, construct validation study. Infant Behavior and Development, 5, 397-410.

Olson, S. L., Bates, J. E., \& Bayles, K. (1984). Mother-infant interaction and the development of individual differences in children's cognitive competence. Developmental Psychology, 20, 166-179.

Parpal, M., \& Maccoby, E. E. (1985). Maternal responsiveness and subsequent child compliance. Child Development, 56, 1326-1334.

Patterson, G. R. (1982). Coercive family processes. Eugene, OR: Castalia.

Pelham, W. E., \& Bender, M. E. (1982). Peer interactions of hyperactive children: Assessment and treatment. In K. D. Gadow \& I. Bialer (Eds.), Advances in learning and behavior difficulties (Vol. 1, pp. 365-436). Greenwich, CT: JAI Press.

Pettit, G. A., \& Bates, J. E. (1984). Continuity of individual differences in the mother-infant relationship from six to thirteen months. Child Development, 55, 729-739.

Schaffer, H. R. (1984). The child's entry into a social world. London: Academic Press.

Schaffer, H. R., \& Crook, C. (1979). Maternal control techniques in a directed play situation. Child Development, 50, 989-996.

Schaffer, H. R., \& Crook, C. (1980). Child compliance and maternal control techniques. Developmental Psychology, 16, 54-61.

Sroufe, L. A. (1983). Infant-caregiver attachment and patterns of adaptation in preschool: The roots of maladaptation and competence. In M. Perlmutter (Ed.), Minnesota Symposium in Child Psychology: Vol. 16 (pp. 14-23). Minneapolis: University of Minnesota.

Thomas, A., Chess, S., \& Birch, H. (1968). Temperament and behavior disorders in children. New York: New York University Press.

Vygotsky, L. S. (1962). Thought and language. Cambridge, MA: M.I.T. Press.

Wertsch, J. (1984). The zone of proximal development: Some conceptual issues. In B. Rogoff \& J. B. Wertsch (Eds.), Children's learning in the "zone of proximal development." In W. Damon (Ed. in chief), New directions for child development (No. 23), San Francisco: Jossey-Bass. 